\title{
Performances of modern domestic hot-water stores
}

\author{
Roman Spur ${ }^{a}$, Dusan Fiala ${ }^{b, *}$, Dusan Nevrala ${ }^{c}$, Doug Probert ${ }^{\mathrm{d}}$ \\ a Department of Environmental and Building Services, Faculty of Civil Engineering, \\ Czech Technical University in Prague, Czech Republic \\ ${ }^{\mathrm{b}}$ Institute of Energy and Sustainable Development, De Montfort University, Leicester, UK \\ ${ }^{\mathrm{c}}$ Enplan - heating technology company, Pod vodovodem, Prague, Czech Republic \\ d School of Engineering, Cranfield University, Bedford, UK
}

Available online 29 November 2005

\begin{abstract}
Several designs of domestic hot-water (DHW) store, including those with immersed heatexchangers (HXs), are commercially available. So there is a need for a method that accurately assesses their effectivenesses. In this study, the behaviours of a novel stratified, and two standard, stores were analyzed. The TRNSYS simulation software was enhanced to simulate the functioning of those stores. The resulting mathematical model was validated using measurements obtained from experiments, which required a realistic daily DHW draw-off for testing the DHW systems. Evaluation of a user-related effectivenesses (URE) for each of the three tanks tested showed that the inner configurations of: (i) the tank and (ii) the immersed HX can significantly affect the store's performance. The stratified store was up to $32 \%$ more effective than the commonly employed commerciallyavailable store.

(c) 2005 Elsevier Ltd. All rights reserved.
\end{abstract}

Keywords: DHW store; Immersed heat-exchanger; Store's performance; Experimental analysis

\section{Introduction}

Some of the DHW stores still on the market use the volumetric content of the tank as the store for the hot water. Other, more modern, designs employ water flowing through a HX, immersed in the hot water of the tank, for the supply of hot water to the householder because they appear to be more effective. The relative performances of different DHW

\footnotetext{
* Corresponding author. Tel.: +44 0116257 7971; fax: +44 01162577981.

E-mail address: dfiala@dmu.ac.uk (D. Fiala).
} 


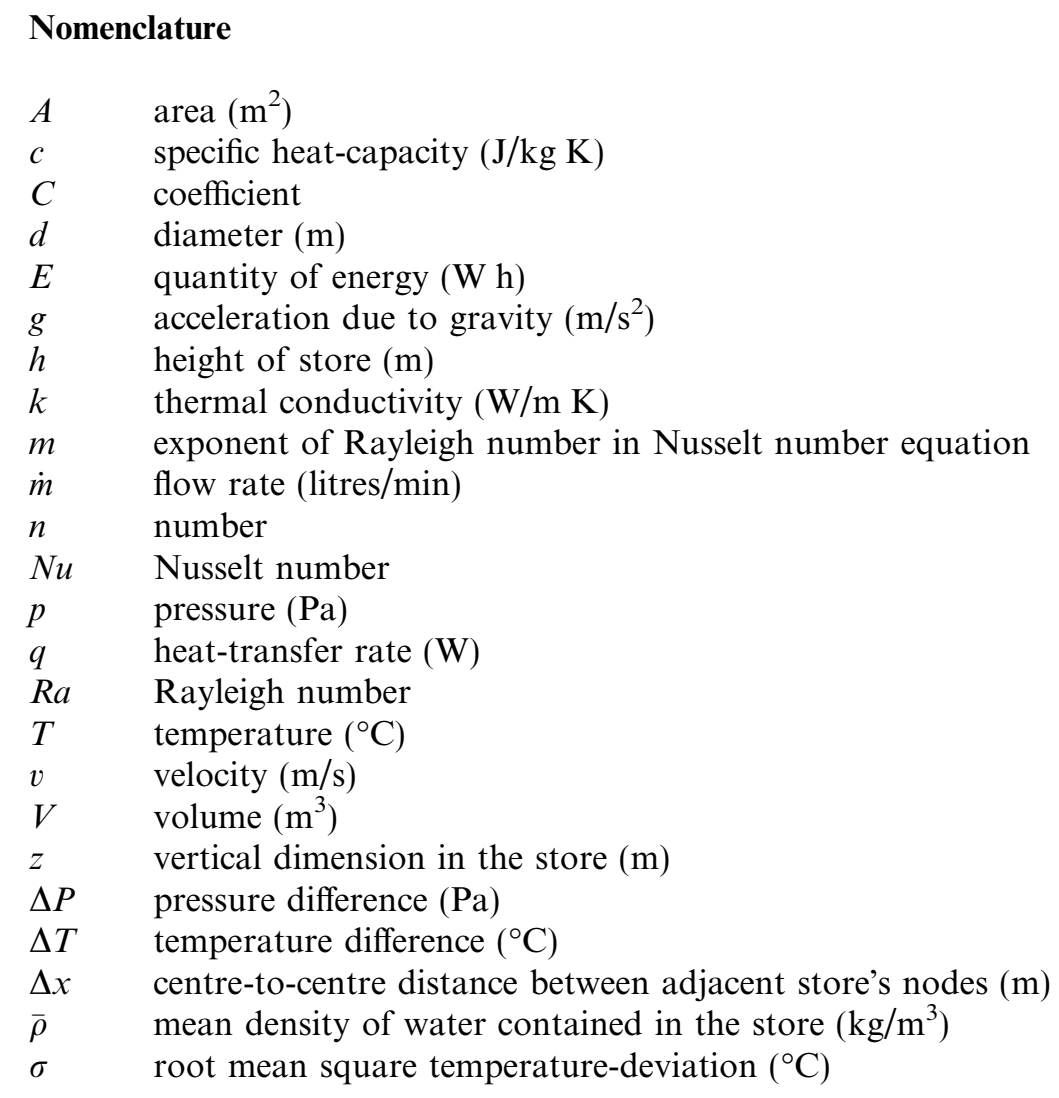

\section{Subscripts}

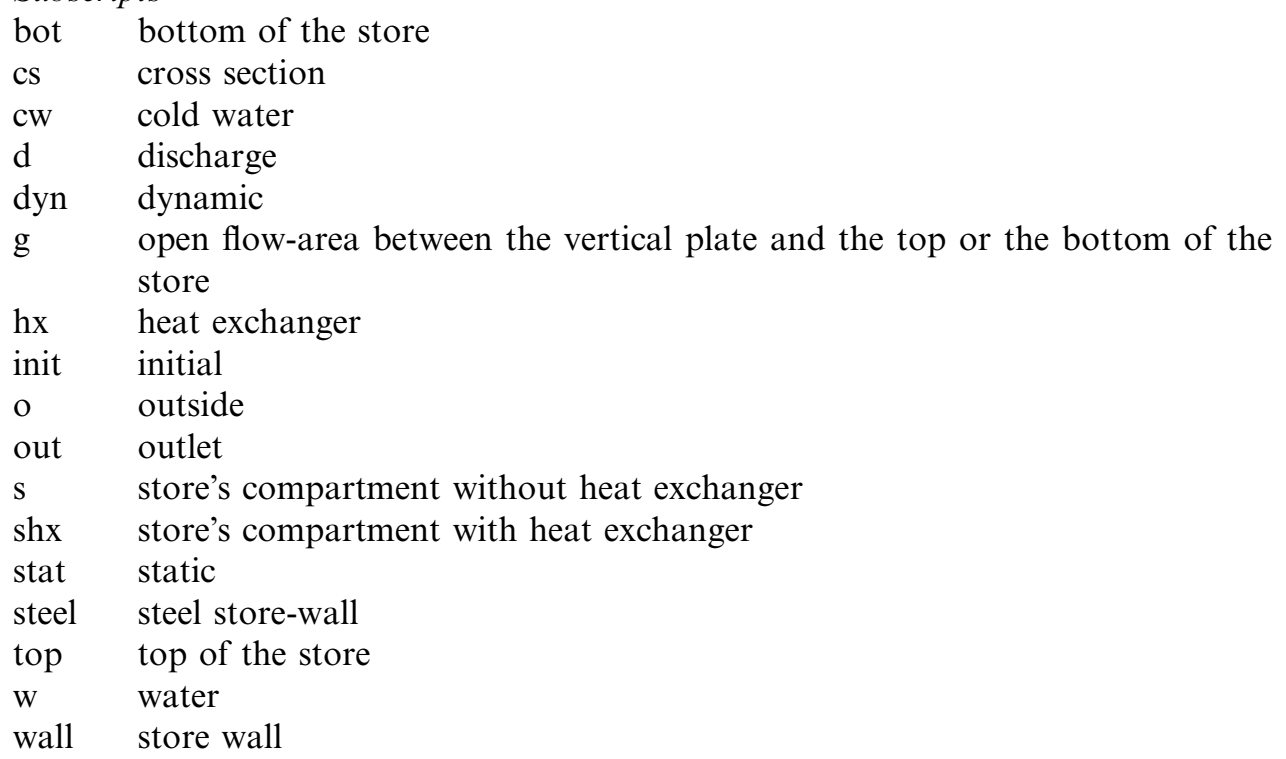


$\begin{array}{ll}\text { Abbreviations } \\ \text { CW } & \text { cold water } \\ \text { DHW } & \text { domestic hot-water } \\ \text { HX } & \text { heat exchanger } \\ \text { PC } & \text { personal computer } \\ \text { RDP } & \text { realistic daily-profile }\end{array}$

Shx1, Shx2 upper and lower outer stores with heat-exchanger, respectively

S1, S2 upper and lower inner parts of the store, respectively

TRNSYS transient systems simulation program

URE user-related effectiveness

stores are however difficult to predict because of the various stores' heat-losses, stratification behaviours and performances of the immersed HXs.

The testing procedures have employed different DHW withdrawal-profiles (i.e., extraction rate versus time) to determine the performances of individual components and of the whole DHW system. The profiles used varied from that with a constant flow-rate draw-off, lasting usually several minutes, to schemes that attempt to simulate a more realistic dailyprofile [1]. Unfortunately, the majority of those profiles were not based on real-world data obtained from field studies. A recent study [2] revealed the influence of the choice of the DHW draw-off profile on conclusions concerning the dynamic behaviour of the store: short and medium draw-offs have significant effects on both: (i) the water-temperature recovery in the HX and (ii) the performance of the store. Hence, this study uses realistic daily-profiles (RDPs) based on field measurements, which replicate statistically the average daily DHW draw-off profiles of European households.

The behaviours of commonly-used DHW-store types were modelled using TRNSYS simulation software. The study involved the development and validation of a new TRNSYS model incorporating an enhanced dynamic model of the behaviour of the HX immersed in a temperature-stratified store. Extensive experimental trials have been conducted to provide the measurements necessary to validate the predictions from the new simulation model.

\section{Stratified DHW store with an immersed HX}

The novel, relatively small, stratified store considered here is highly effective at storing heat and supplying DHW: it balances the store's capacities for space heating and DHW and maintains effective stratification. This has been made possible by the patented DHW HX arrangement [3], which enables an effective extraction of the stored heat from the bottom of the store, while keeping the top of the store hot in readiness to meet spaceheating demand. Internal construction allows a high degree of temperature stratification in the store to be achieved.

\subsection{The stratified store}

This is subdivided into an upper and lower part - see Fig. 1. The lower part (S2) is for preheating the DHW and could be energized by alternative systems, such as a solar 


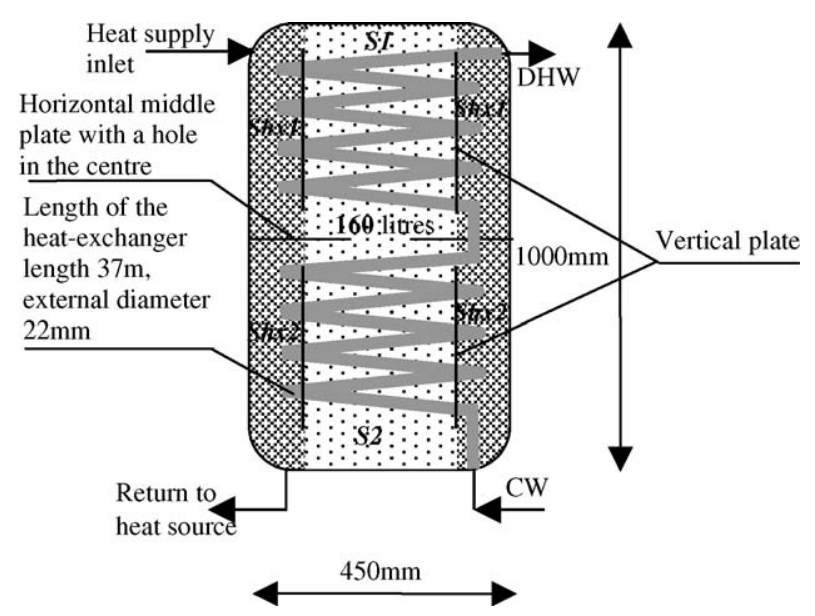

Fig. 1. The novel stratified store.

collector or a heat pump. The upper part (S1) is used for heating. The DHW is supplied with heat from a boiler. The division of the store into upper and lower regions is accomplished by using a horizontal plastic plate (see Fig. 1), which inhibits the flow vertically. Nevertheless, a hole in the middle of the horizontal divider plate permits water to flow between the two regions as a result of either charging or buoyancy. The DHW is heated in the immersed helical copper-pipe HX. The upper and lower parts of the HX are of the identical lengths located in two columns connected through the horizontal middle-plate. To obtain improved rates of heat transfer between the store water and that in the HX pipe, vertical annular plates are located along the HX (i.e., Shx1 and Shx2). These vertical plates cause the water velocity outside the HX to increase so increasing its rate of convective heat-gain.

\subsubsection{Simulation model of the behaviour of the stratified store}

The enhanced TRNSYS simulation software [4] was used to model the behaviour of the stratified store containing the immersed HX. In this study, the TRNSYS for the detailed fluid store-tank TYPE 60 [4] was used to simulate the temperature stratification along the store height and to predict the outlet temperature of the DHW from the HX. The type 60 enables a user-specified number of volume nodes, into which the store is subdivided vertically, to define the degree of thermal stratification (ranging from 1 node for a mixed store to 100 nodes for a fully-stratified store).

Unfortunately, neither the TYPE 60 nor the other TRNSYS behavioural types, allow for variations of the internal design of the store considered in this study. Moreover, the TRNSYS type does not take into account the heat-storage volume of the HX, which is an important factor in any realistic simulations of the dynamic thermal behaviour of the store and the DHW usage. Thus it was necessary to develop an enhanced store-model, which was accomplished by combining the existing TYPE 60 with a theoretical knowledge of the stratified-store's behaviour and an enhanced dynamic model of the behaviour of the immersed HX, to facilitate an adequate simulation of the behaviour of the store - HX system, even under the rapid transient conditions represented, for example, by sequences of short and/or medium duration DHW draw-offs. 
The TRNSYS store type 60 was enhanced by taking into account the volume of the exchanger's pipe, in which heat can be stored and from which it can be extracted.

2.1.1.1. Multi-unit dynamic model of the store's behaviour. The simulation model of the stratified store - see Fig. 2 - consists of four compartments, namely the outer part of the store with the immersed HX at its top (Shx1) and its bottom (Shx2), and the inner upper (S1) and the inner lower (S2) parts of the stratified store. The behaviour of each compartment was modelled by TRNSYS Type 60 divided into five nodes of $10 \mathrm{~cm}$ vertical thickness, which provided sufficient resolution for the purposes of the study. Both the upper and the lower components (S1 and S2) are linked together with the respective outer compartments (Shx1 and Shx2) via connections a and c, and b and d, respectively. These connections simulate the flows through the openings between the vertical plate and the top and the bottom of the store, respectively. The connections e and f linking the upper Shx 1 and lower Shx2 regions of the store simulate the heat-transfer paths through store wall and plastic plate; connections $\mathrm{g}$ and $\mathrm{h}$ linking the upper and lower regions of the store, $\mathrm{S} 1$ and $\mathrm{S} 2$, respectively, indicate the heat-transfer paths through the middle plate and the flow of water via the hole in the middle plate of the store.

The flows between compartments were modelled to represent those of the water in the store. The flows between the outer compartments (Shx1 and Shx2) and inner compartments ( $\mathbf{S} 1$ and $\mathbf{S} 2$ ) are indicated by $\mathbf{a}, \mathbf{b}$ and $\mathbf{c}, \mathbf{d}$ and depend on the corresponding values of the static pressure-difference $\Delta P$, as described by Bernoulli's equation for one-dimensional, steady flows [5], where $p_{\text {stat }}$ is the static pressure and $p_{\text {dyn }}$ the dynamic pressure: i.e.,

$$
\Delta P=\left(p_{\text {stat }, \mathrm{shx}}+p_{\mathrm{dyn}, \mathrm{shx}}\right)-\left(p_{\mathrm{stat}, \mathrm{s}}+p_{\mathrm{dyn}, \mathrm{s}}\right)+\rho g\left(z_{\mathrm{shx}}-z_{\mathrm{s}}\right) .
$$

Due to the very slow flows within individual compartments, the part of the equation incorporating the dynamic pressures can be neglected without, in this instance, a significant loss of accuracy. Considering furthermore the fact that the connected compartments Shx1-S1 and Shx2-S2 are of the same height, the expression $\rho g\left(z_{\mathrm{shx}}-z_{\mathrm{s}}\right)$ becomes zero.

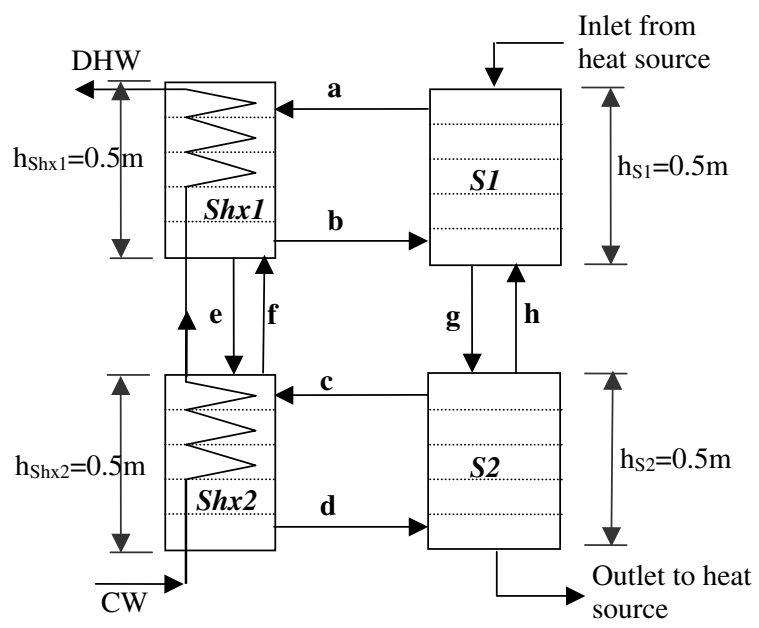

Fig. 2. The modelled store with heat-flow paths. 
The flow rate between pairs of compartments can therefore, to a good approximation, be expressed as a function solely of the difference in the static pressures. With $p_{\text {stat }}=\bar{\rho} h g$ being the static pressure at the bottom of a compartment and $\bar{\rho}$ the average water-density in the compartment, then

$$
\Delta P=\bar{\rho}_{\mathrm{shx}} g h_{\mathrm{shx}}-\bar{\rho}_{\mathrm{s}} g h_{\mathrm{s}} .
$$

This pressure difference is the driving force for the mass flow between the compartments (connection $\mathrm{b}$ and $\mathrm{d}$ - see Fig. 2) and thus equals the dynamic pressure $\bar{\rho} v^{2} / 2$ of the flow: i.e.,

$$
\bar{\rho}_{\mathrm{shx}} g h_{\mathrm{shx}}-\bar{\rho}_{\mathrm{s}} g h_{\mathrm{s}}=\frac{\bar{\rho} v^{2}}{2}
$$

where the density $\bar{\rho}$ is calculated from the average temperature of each compartment [5]. Eqs. (2) and (3) can be used to calculate the corresponding of flow-rate $\dot{m}$ (for $\mathbf{b}$ and d) [5] via:

$$
\dot{m}=C_{\mathrm{d}} A_{\mathrm{g}} \sqrt{2 \Delta P \bar{\rho}}
$$

where $C_{\mathrm{d}}$ is the discharge coefficient and $A_{\mathrm{g}}$ is the aperture area (of the low-level openings connecting the pairs of inner and outer compartments). This flow-rate is calculated separately for connections $\mathbf{b}$ and $\mathbf{d}$. The discharge coefficient $C_{\mathrm{d}}$ was obtained from independent experimental data [6] and equals 0.08. Due to the mass equality between compartments (Shx1 and S1, as well as Shx2 and S2), the rate of mass flow through connections $\mathbf{a}$ and $\mathbf{c}$ equals that due to the corresponding contra-current flows $\mathbf{b}$ and $\mathbf{d}$, respectively. Various tests have shown that there is virtually no mass flow between compartments $\mathrm{S} 1$ and S2. Nevertheless, heat transfer due to conduction between S1 and S2 takes place and is considered in the model. The thermal resistance of the horizontal plastic-plate, dividing the store into the upper and lower regions, is small and can thus, for practical purposes, be neglected. Therefore, the rate of heat conduction between S1 and S2, including an appropriate contribution due to the water, and between Shx1 and Shx2 can be estimated using the following equation, which also considers the heat transfer through the vertical shell of the store [4]:

$$
q=-\left(k_{\mathrm{water}}+k_{\mathrm{wall}}\right) A_{\mathrm{cs}}\left(\frac{\Delta T}{\Delta x}\right)
$$

where

$$
k_{\text {wall }}=k_{\text {steel }} \frac{A_{\mathrm{cs}, \text { store,wall }}}{A_{\mathrm{cs}, \text { store }}} .
$$

$\Delta T$ is the temperature difference and $\Delta x$ the centre-to-centre distance between adjacent store nodes.

This rate of heat transfer $q$ can be considered as provided by a fictitious low flow-rate $\dot{m}_{\text {cond }}$ between the store S1 and S2, and Shx 1 and Shx2, respectively, and evaluated using the equation:

$$
\dot{m}_{\mathrm{cond}}=\frac{q}{C_{\mathrm{w}}\left(T_{\mathrm{S} 2, \mathrm{top}}-T_{\mathrm{S} 1, \mathrm{bot}}\right)} .
$$

2.1.1.2. Enhanced dynamic model for the immersed heat-exchanger. The behaviour of the HX in the TYPE 60 store has been described by a steady-state model that ignores any heat storage in the water volume within the HX. However, the transient effects of 
the HX's depletion and recovery, after and before respectively a DHW withdrawal, caused by the heat exchange with the water in the store, have to be considered in order to predict accurately the time-varying DHW outlet temperature: (i) during the whole period of a short draw-off and (ii) at the beginning of any longer draw-off, when the water in this HX can reach the store's temperature. It was therefore desirable to extend the mathematical model of the HX's dynamic behaviour by accounting for the presence of the thermal mass of the water in the HX. For this purpose, the existing TRNSYS Type 31 of a pipe simulating the heat exchange of the pipe with the environment was introduced. The HX of the store was divided into six equal parts (three in the Shx1 and three in the Shx2), which were connected in series with a Type 31 pipe representing each part - see Fig. 3.

The overall heat-transfer parameter $U A_{\mathrm{hx}}$ needed to calculate the rate of heat exchange between the HX and the water in the store is predicted iteratively for each part of the HX. The outside surface's convection-coefficient $h_{\mathrm{o}}$ is obtained as

$$
h_{\mathrm{o}}=\frac{N u}{d_{\mathrm{o}}}
$$

where $N u=C R a^{m}, N u$ being the heat-transfer Nusselt number, $R a$ the Rayleigh number of the flow, and $d_{\mathrm{o}}$ the outside diameter of the HX's coil. The constant coefficient $C$ and the exponent $m$ were determined, from measured data obtained for that store [6], by means of a statistical regression-analysis. According to [7], $m=0.25$ for laminar flow around the

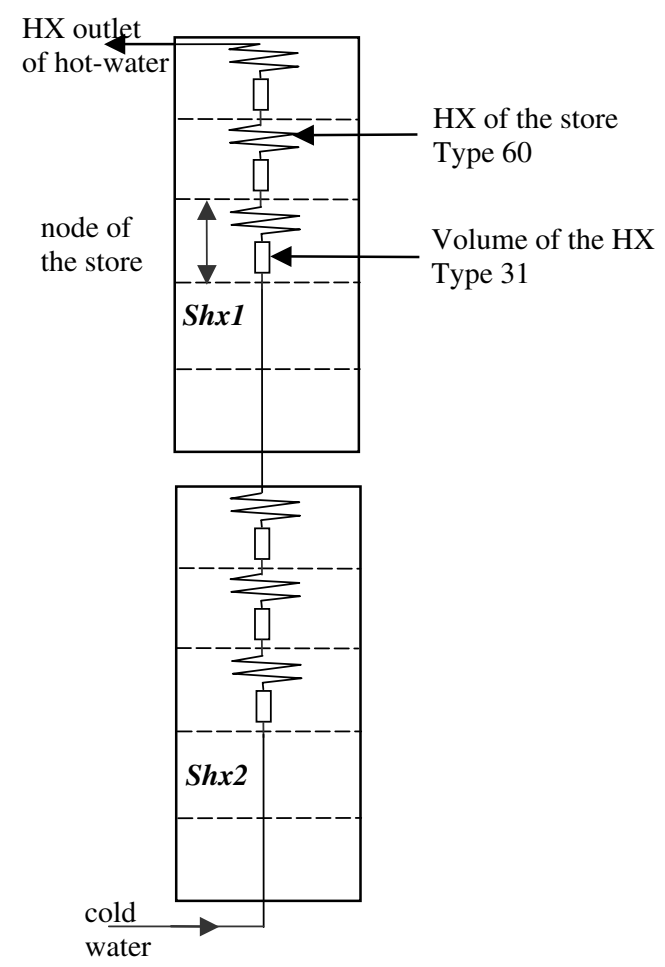

Fig. 3. The enhanced HX model. 


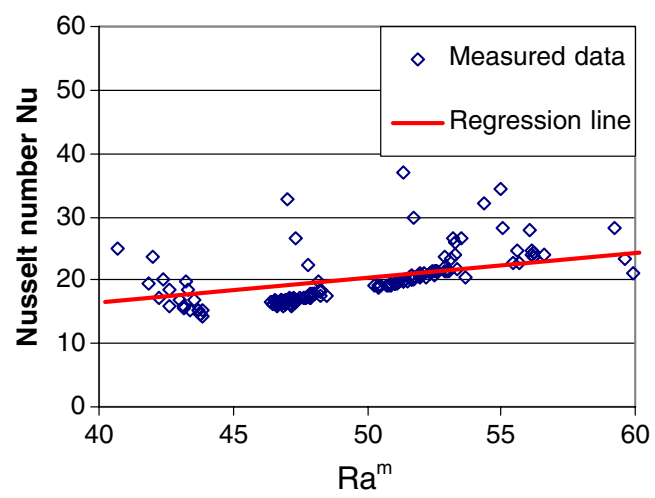

Fig. 4. Regression line through the measured data [6].

outside of the HX with values of $C$ ranging between 0.1 and 0.7 . The recommended value for $C$ is typically 0.5 [4]. In this study, the coefficient $C$ was obtained by a regression analysis (with $m=0.25$ - see Fig. 4) via a preliminary experiment [6]. Hence $C=0.410 \pm 0.007$, which was the value used in the present model.

\section{Experimental investigations}

As a part of this study, several tests were carried out to provide data for the validation of the complete simulation model. The test apparatus (see Fig. 5) consisted of the investigated stratified store (160 litres), a charging electric-heater, valves, pumps and a data recorder with temperature and flow-rate sensors. The system's components and locations of the sensors are shown schematically in Fig. 6. Five temperature sensors (T-type thermocouples $(\mathrm{Cu} / \mathrm{Cu}-\mathrm{Ni})$ with an accuracy $\left.\pm 0.5^{\circ} \mathrm{C}\right)$ were situated at different heights within the store in order to monitor the thermal stratification. Additionally, the temperatures of the cold water, at the inlet, and the warmer water at the outlet of the HX, and that of the postmix DHW after the thermostatic mixing-valve were measured along with the water flowrate of the DHW. The measurements were recorded by a data logger (Grant-Squirrel 1203) at 4-s intervals.

The measurements were carried out for different DHW draw-off profiles. At the beginning of each test, the entire store was charged to an initial temperature of about $80{ }^{\circ} \mathrm{C}$. At that time a circulating pump (see Fig. 6) mixed the water so ensuring a homogeneous temperature in the tank.

\section{Validation}

Once the enhanced TRNSYS model of the behaviour of the stratified store had been set up, it was used to simulate the experimental trial in order to compare the predicted with the measured temperatures. The validation exercise was accomplished in two phases. The first focussed on the detailed response of the HX's outlet-temperature to a sequence of three draw-offs. In the second phase, the ability of the new simulation store model was tested regarding its behaviour, over a day, using a DHW withdrawal profile. In households, the DHW system is fitted either with, or without, a thermostatic mixing-valve. 


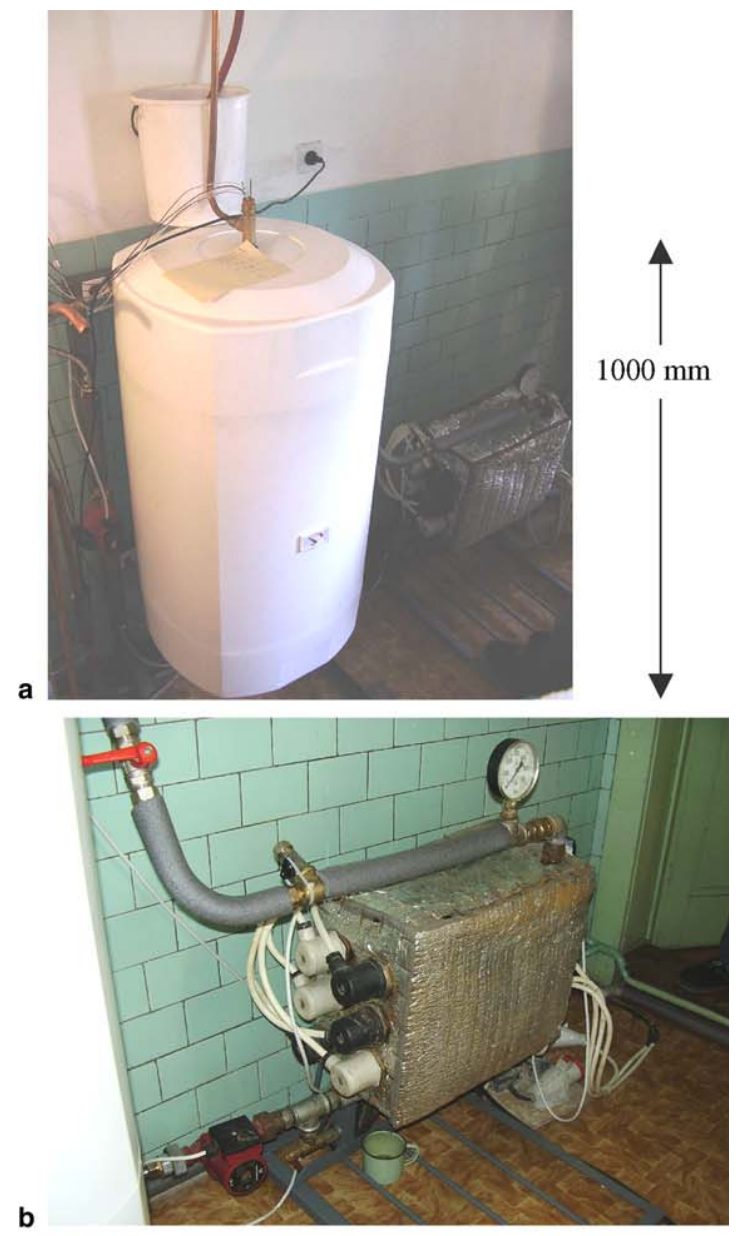

b

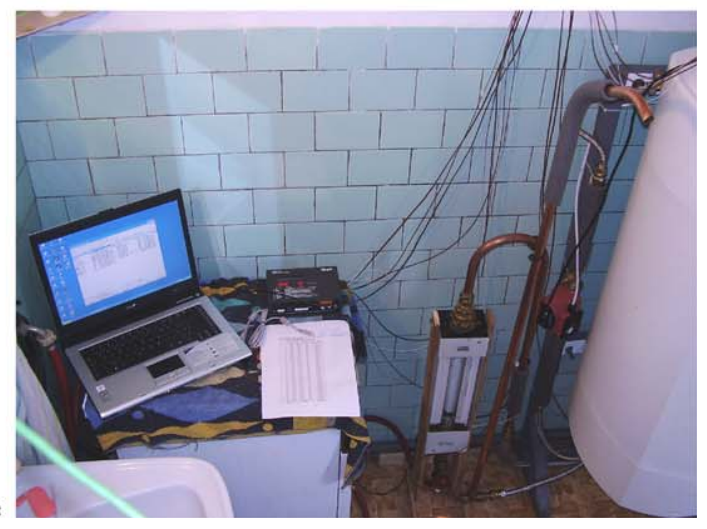

Fig. 5. Test apparatus for measurements under realistic draw-off conditions: (a) the investigated tank connected through an open expansion vessel to the heat-distribution circuit; (b) energy supply source: the electric-heater unit connected to the tank; (c) recording equipment: data logger squirrel connected to the temperature sensors, laptop computer and flow meter. 


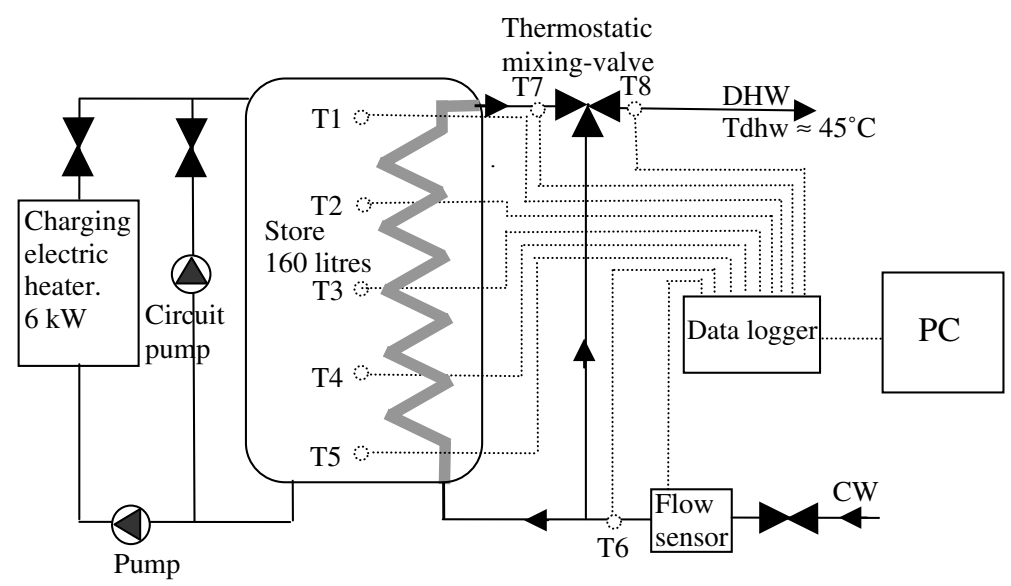

Fig. 6. Schematic of the test apparatus.

Hence, this phase was divided into two independent parts in which the performance of the model was evaluated under these two circumstances.

The first test consisted of three draw-offs (with withdrawals of 10, 10 and 40 litres, and with a flow-rate through the HX of 10, 6 or 12 litres/min). In Fig. 7, the temperatures at the top $\left(T_{\text {top }}\right)$ and at the bottom $\left(T_{\text {bot }}\right)$ of the store, and the outlet temperature of the HX ( $\left.T_{\mathrm{hxOut}}\right)$, and the temperature of cold water $\left(T_{\mathrm{cw}}\right)$ are plotted together with the flow-rate $\left(\dot{m}_{\mathrm{hx}}\right)$ through the HX. The predicted temperature at the top of the store replicated well the corresponding experimental data except for short temperature-drops measured at the beginning of each draw-off. The predicted temperatures at the bottom of the store ( $\left.T_{\text {bot }}\right)$ were corroborated by the experiment. The simulated temperatures of the HX also reproduced well the corresponding measured values, typically to within $\pm 1.9{ }^{\circ} \mathrm{C}$.

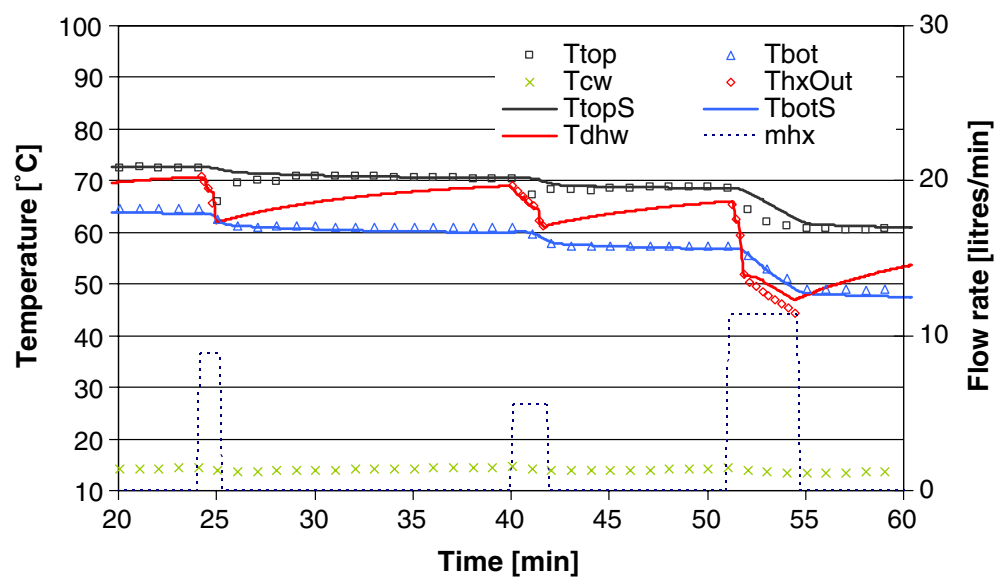

Fig. 7. Comparison of measured (data points) and simulated (lines) temperatures at the top ( $\left.T_{\text {top }}\right)$, and at the bottom $\left(T_{\text {bot }}\right)$ of the store, the outlet temperature $\left(T_{\text {hxOut }}\right)$ of the HX and the temperature of the cold water ( $\left.T_{\mathrm{cw}}\right)$. Both the values of the simulated or measured flow-rate $\left(m_{\mathrm{hx}}\right)$ through the HX are indicated by the dashed lines. 
Fig. 8 displays the results of a whole-day's simulation together with the measured data for the condition without a thermostatic mixing-valve and using a realistic daily DHW draw-off profile with a total volume of 180 litres. All simulated temperatures realistically corresponded with the measurements. At the end of the day, the predicted temperatures at the top of the store deviated by $2{ }^{\circ} \mathrm{C}$ and at the bottom of the store by $2.5^{\circ} \mathrm{C}$ from the measured values. The difference between the predicted and measured energies withdrawn by the DHW was about $0.6 \%$.

To obtain representative information on the characteristic discrepancies between the simulation and the measurements over the duration of a test, the root mean square deviations between measured and simulated temperatures were obtained from

$$
\sigma=\sqrt{\sum_{i}^{n} \frac{\Delta T^{2}}{n} .}
$$

In the first validation test, the temperature discrepancies were $\sigma_{T_{\text {top }}}=0.8^{\circ} \mathrm{C}$ and $\sigma_{T_{\text {bot }}}=0.9^{\circ} \mathrm{C}$ at the top and bottom of the store, respectively, and $\sigma_{T_{\text {hxout }}}=1.6^{\circ} \mathrm{C}$ for the $\mathrm{HX}$ outlet. For the second test, the characteristic differences were $\sigma_{T_{\text {top }}}=1.2{ }^{\circ} \mathrm{C}$ at the top, $\sigma_{T_{\text {bot }}}=1.7^{\circ} \mathrm{C}$ at the bottom of the store and $\sigma_{T_{\text {hXout }}}=1.6^{\circ} \mathrm{C}$ at the $\mathrm{HX}$ outlet.

The "whole-day" experiment, with the thermostatic mixing valve being used, revealed several differences between the ideal simulation and realistic conditions. The measurements exhibited fluctuating, rather than constant, post-mix temperatures of the thermostatic mixing-valve during a draw-off. Particularly at the beginning of each draw-off, the DHW temperature oscillated significantly due to the mixing-valve attempting to adjust to the desired temperature of $T_{\mathrm{dhw}}=45^{\circ} \mathrm{C}$. Furthermore, the assumed ideal constant-temperature of the cold water $\left(T_{\mathrm{cw}}=10^{\circ} \mathrm{C}\right)$ was not maintained. Rather, the real temperature of the cold water varied by about $2{ }^{\circ} \mathrm{C}$ during each draw-off. The measured $T_{\mathrm{cw}}$ temperature usually reached $14^{\circ} \mathrm{C}$; occasionally, however, $T_{\mathrm{cw}}$ climbed to $20^{\circ} \mathrm{C}$. In order to

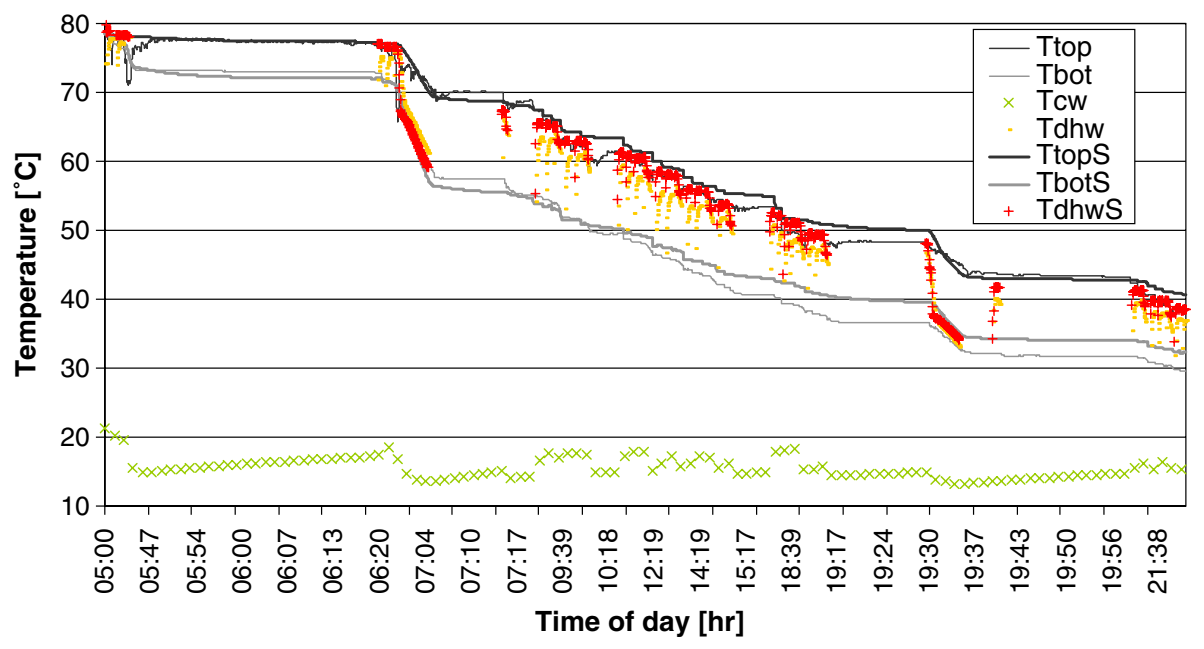

Fig. 8. Comparison of measured (data points) and simulated (lines) temperatures at the top $\left(T_{\text {top }}\right)$, and at the bottom ( $\left.T_{\mathrm{bot}}\right)$ of the store, the outlet temperature $\left(T_{\mathrm{hxOut}}\right)$ of the HX and the temperature of the cold water $\left(T_{\mathrm{cw}}\right)$ for the stratified store, without the thermostatic mixing-valve, during a day. 


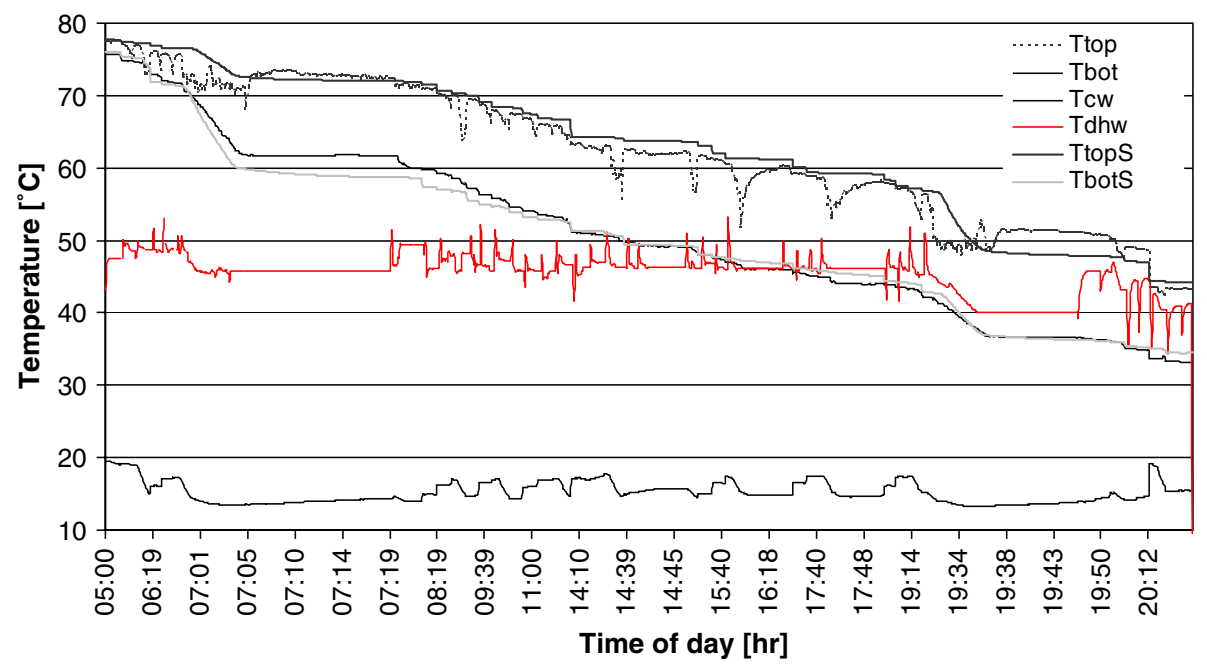

Fig. 9. Comparison of measured (data points) with simulated (lines) temperatures at the top ( $\left.T_{\text {top }}\right)$, and at the bottom $\left(T_{\text {bot }}\right)$ of the store, the outlet temperature $\left(T_{\text {hxOut }}\right)$ of the HX and the temperature of the cold water $\left(T_{\mathrm{cw}}\right)$ for the stratified store with the thermostatic mixing-valve, in the course of the day.

enable a comparison of the simulated results with the measured data, the temporal fluctuations in $T_{\mathrm{cw}}$ and $T_{\mathrm{dhw}}$ were considered in the simulations as well. The results of the comparison are plotted in Fig. 9.

\section{Evaluation of the performances of different stores}

\subsection{Tested stores}

In this experimental study, three different stores were used - see Fig. 10. Store A is the novel stratified-store described in Section 2. It was chosen in order to determine the effect of an improved inner store design on the performance of the store. Stores B and C are commonly used. Store B contains a HX which is coiled upward from the bottom to the

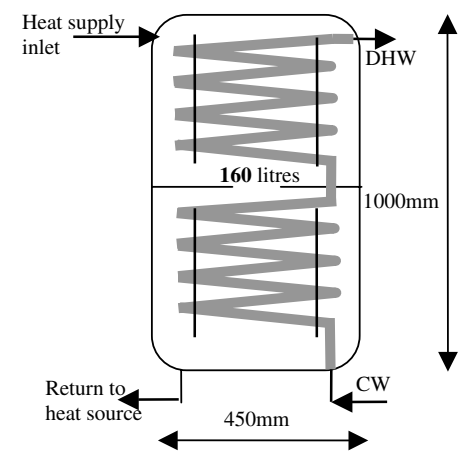

Store A

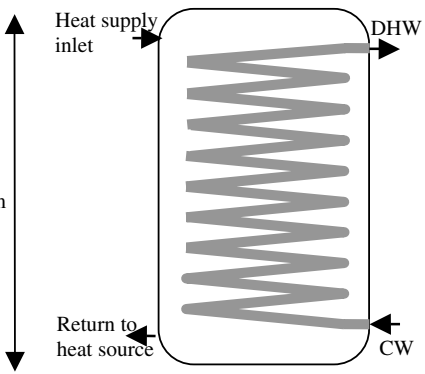

Store B

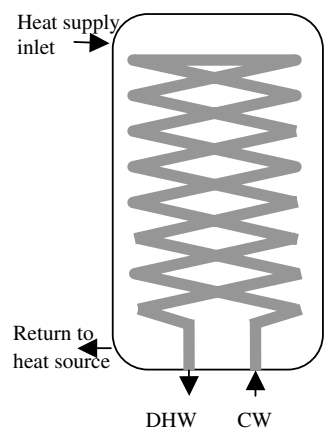

Store C

Fig. 10. Schematic designs of stores A, B and C as used in the analysis. 
top of the store. Store's C HX coils upward from the bottom to the top of the store and downward from the top to the bottom of the store. The inlet is at the bottom and the outlet is at the top of the store. All the stores were of identical volume (160 litres), height (1 m) and diameter $(0.45 \mathrm{~m})$ and coated with a thermal-insulation blanket $4 \mathrm{~cm}$ thick. The length and outside diameter of the immersed copper-coil HX were $37 \mathrm{~m}$ and $22 \mathrm{~mm}$, respectively.

\subsection{Testing procedure}

One aim of the study was to devise a testing procedure using which the performance of different stores could be evaluated under realistic conditions by either simulation or experiment.

The procedure involves an initial charging of the store at $80^{\circ} \mathrm{C}$, followed by a discharge of the store using a realistic daily DHW draw-off profile obtained from field studies. A range of these profiles is described in [2]. For the purpose of this study, a profile scheme RDP2 was chosen with a total daily withdrawal volume of 180 litres [2]. RDP2 represents an average daily European-household's usage of DHW and thus suited the purpose of the investigation. This DHW profile includes 42 draw-offs (short, medium and shower) and is shown graphically in Fig. 11. In order to provide DHW at the required temperature, a thermostatic mixing-valve was included. The temperature of the DHW was chosen to be $45^{\circ} \mathrm{C}$, which is the commonly-accepted value. The temperature of the cold water was assumed to be $10^{\circ} \mathrm{C}$. So the thermostatic mixing valve, which mixes the HX outlet water with the cold water, was set to $T_{\mathrm{dhw}}=45^{\circ} \mathrm{C}$. In practice, the temperature of the post-mix DHW can oscillate mainly at the very beginning of a drawoff. Therefore, the suggested test procedure was run both with, and without, the thermostatic mixing valve.

Once the system's configuration is decided and the process of testing agreed, it was necessary to establish the comparison procedure.

\subsubsection{Comparison of the behaviours, with and without the thermostatic mixing-valve being present}

In order to evaluate the store's performance without the influence of any other system components, the performance of the store was examined initially without a thermostatic mixing-valve. This test better reveals the differences in the performance between individual stores. Subsequently, the performance of the store under conditions which

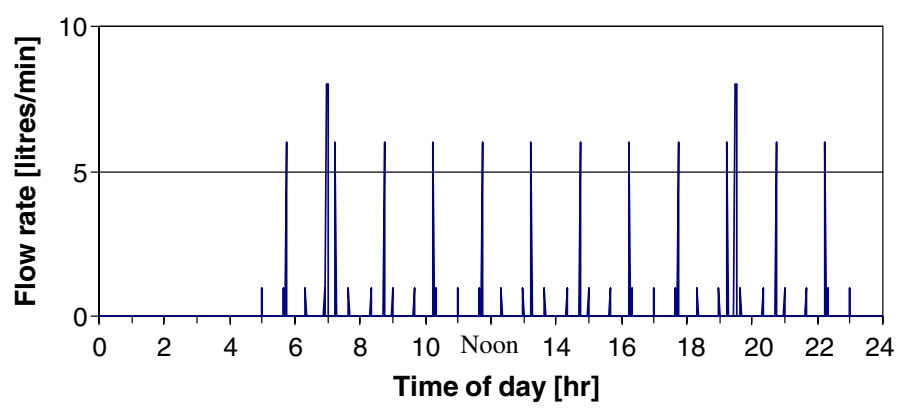

Fig. 11. Medium-load RDP2. Flow rates and occurrences of draw-offs during the day. 
are normally met in practice, i.e., in combination with a thermostatic mixing-valve, was investigated.

\subsection{Simulation results (see Fig. 12)}

Store $\mathrm{C}$ achieved less stratification compared with those in stores $\mathrm{A}$ and $\mathrm{B}$. In store $\mathrm{C}$, the downward coiling of the HX pipe was responsible for a lower temperature in the $\mathrm{HX}$ at the bottom of the store and consequently a lower outlet HX temperature for the DHW. The design of the HX significantly affected the store's performance and disturbed the stratification within the store: the maximum temperature-difference between the top and the bottom of the store hardly reached $8^{\circ} \mathrm{C}$, whereas, in stores $\mathrm{A}$ and $\mathrm{B}$, stratification temperature-differences of about $15^{\circ} \mathrm{C}$ occurred.

The behaviours of stores A and B appeared superficially to be similar. Nevertheless, there are some differences. Store A reached a minimum DHW temperature $T_{\mathrm{dhw}, \min }=32.5^{\circ} \mathrm{C}$, while in the case of store $\mathrm{B}, T_{\mathrm{dhw}, \min }=29.5^{\circ} \mathrm{C}$. The drops in temperature at the $\mathrm{HX}$ outlet in store A, during draw-offs, turn out to be less (on average by about $2{ }^{\circ} \mathrm{C}$ ) compared with those for store B. This was caused by a greater HX recovery in store A, where the design of the store improved the rate of heat transfer into the HX. Hence the temperature within the HX needs a shorter time to approach the temperature of the water at the top of the store.

\subsubsection{Comparison of DHW temperatures, with a thermostatic mixing-valve employed}

An indicator of the stores' performance is a comparison of the outlet DHW volumes at the prescribed temperature level. In this evaluation, with the thermostatic mixing-valve being used, the volumes and temperatures of the withdrawn hot-water below the desired temperature of $T_{\mathrm{dhw}}=45^{\circ} \mathrm{C}$ were compared, in addition to the minimum DHW temperature achieved during the simulation, being predicted.

The hot-water volumes at different temperature ranges, obtained for the three stores, are shown in Fig. 13.

Store A maintained the desired temperature of $45^{\circ} \mathrm{C}$ almost throughout the whole day, except during the evening shower, when the DHW temperature dropped to $T_{\text {dhw,min }}=41.3{ }^{\circ} \mathrm{C}$. In store $\mathrm{B}, T_{\mathrm{dhw} \text {,min }}$ dropped during the evening shower to a value of $T_{\mathrm{dhw} \text { min }}=36.9^{\circ} \mathrm{C}$. One can see that store A supplied the highest volume at the desired DHW temperature, whereas store $\mathrm{C}$ delivered the lowest volume. The relative difference of $\mathrm{DHW}$ volumes at the temperature $T_{\mathrm{dhw}}=45^{\circ} \mathrm{C}$ between stores $\mathrm{A}$ and $\mathrm{B}$ reached about $15 \%$, and between stores $\mathrm{A}$ and $\mathrm{C}$ over $20 \%$. These behavioural differences between stores $\mathrm{A}, \mathrm{B}$ and $\mathrm{C}$ have to be ascribed to the differing HX heat-transfers, recoveries and stratifications in store $\mathrm{A}$ due to the inner configuration of the store.

\subsubsection{Comparison of the DHW equivalent volumes, with a thermostatic mixing-valve employed}

The "equivalent volume", $V_{\text {eq45, }}$, provides information on the capability of the store to deliver the required DHW volume at the desired temperature of $45^{\circ} \mathrm{C}$. This is particularly useful for evaluating the performance of the DHW store without the thermostatic mixing-valve. The exploitable energy is assessed for the volume of withdrawn hot-water at temperatures higher than, or equal to the desired level $T_{\mathrm{dhw}} \geqslant 45^{\circ} \mathrm{C}$. The equivalent 

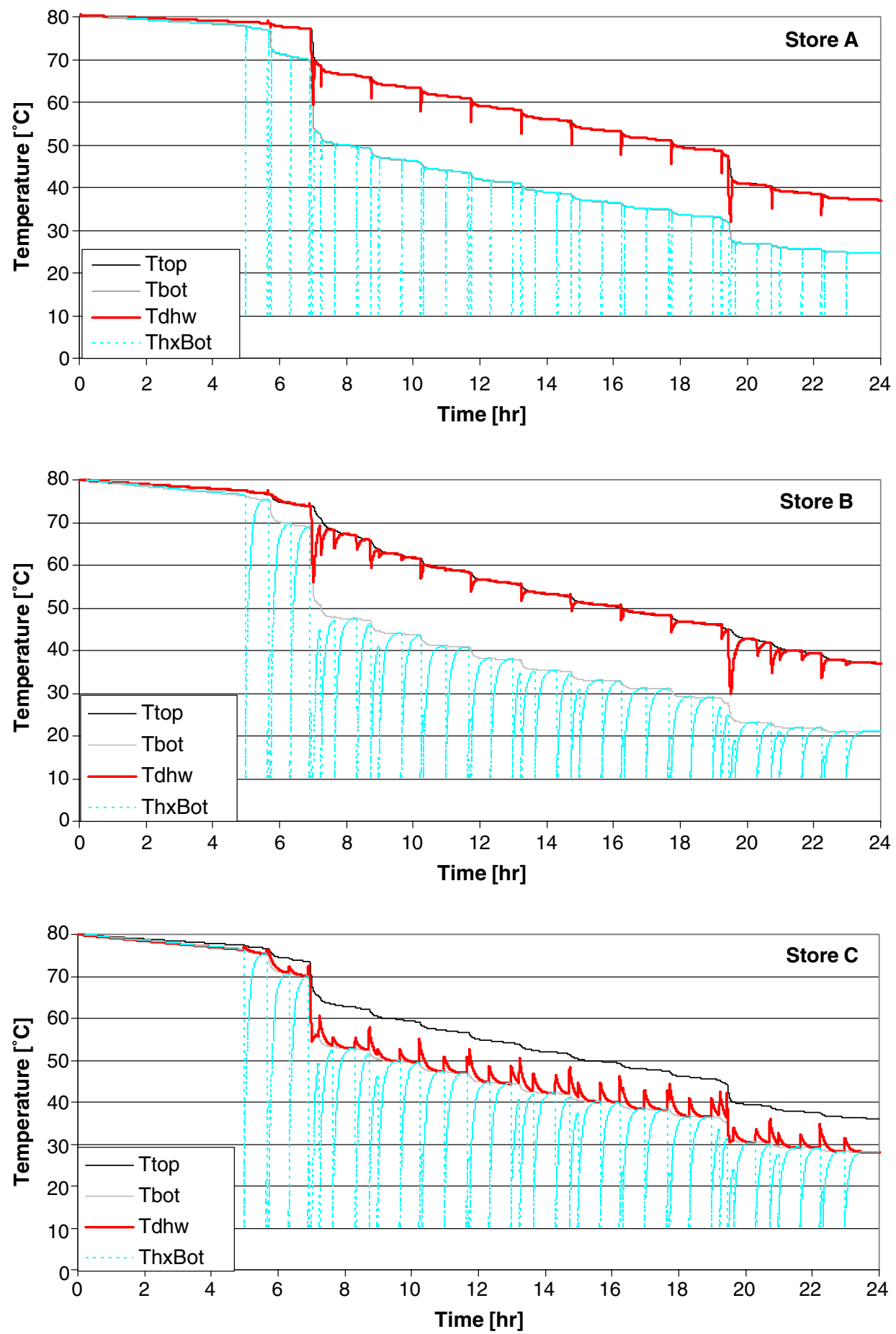

Fig. 12. Simulation results obtained for stores $\mathrm{A}, \mathrm{B}$ and $\mathrm{C}$ without using thermostatic mixing-valves during a day. 


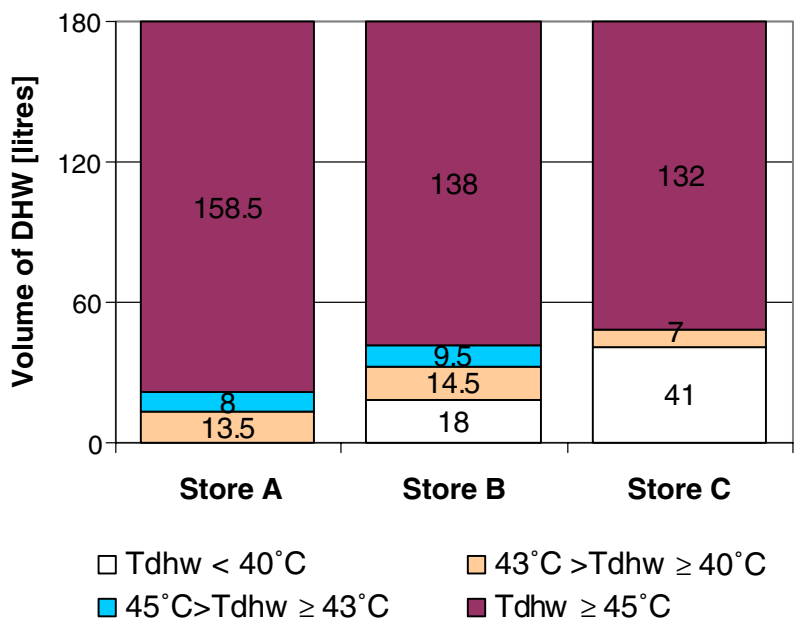

Fig. 13. Performance differences among the stores (equipped with a thermostatic mixing-valve) in terms of the volume of water delivered at the prescribed temperature levels. Plotted withdrawal volumes refer to the temperature intervals of $T_{\mathrm{dhw}} \geqslant 45^{\circ} \mathrm{C}, 45^{\circ} \mathrm{C}>T_{\mathrm{dhw}} \geqslant 43^{\circ} \mathrm{C}, 43^{\circ} \mathrm{C}>T_{\mathrm{dhw}} \geqslant 40{ }^{\circ} \mathrm{C}$ and $T_{\mathrm{dhw}}<40^{\circ} \mathrm{C}$ for each store.

hot-water volume is calculated as the accountable energy $Q_{T}>45{ }^{\circ} \mathrm{C}$ divided by the mean density $\rho$ of the hot water, the heat capacitance $C_{\mathrm{w}}$ and the difference $\Delta T$ between the desired hot-water temperature $T_{\mathrm{dhw}}=45^{\circ} \mathrm{C}$ and the temperature of the cold water $\left(T_{\mathrm{cw}}=10^{\circ} \mathrm{C}\right)$ : i.e.,

$$
V_{\text {equils }}=\frac{Q_{T>45^{\circ} \mathrm{C}}}{\rho C_{\mathrm{w}} \Delta T} .
$$

In Fig. 14, the equivalent volume is shown for each store referred to a hot-water temperature $T_{\mathrm{dhw}}=45^{\circ} \mathrm{C}$.

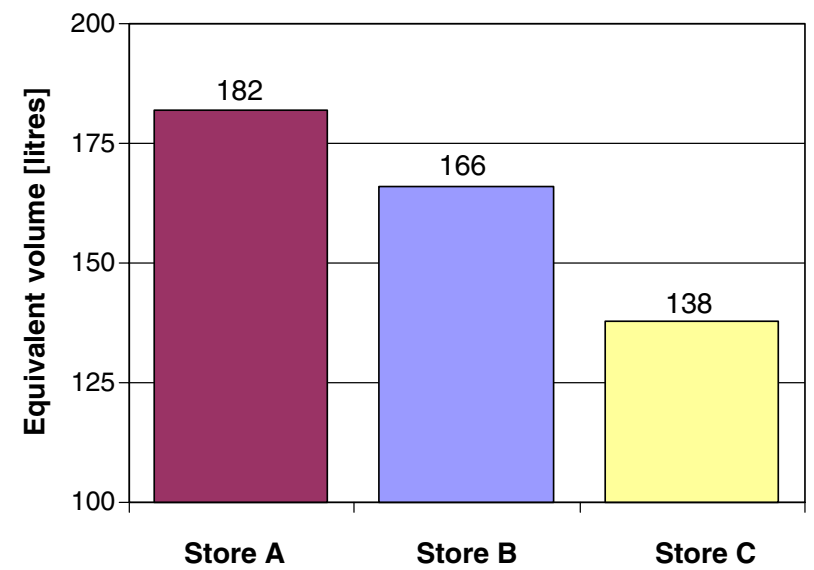

Fig. 14. Equivalent volumes for stores A, B and $\mathrm{C}$ for $T_{\mathrm{dhw}}=45^{\circ} \mathrm{C}$ and $T_{\mathrm{cw}}=10^{\circ} \mathrm{C}$. 
Store A delivered 182 litres, store B 166 litres, and store C provided only 138 litres of hot-water equivalent volume. Thus store $\mathrm{A}$ is about $10 \%$ more effective than store $\mathrm{B}$ and over $32 \%$ more than store $\mathrm{C}$.

\subsubsection{Comparison of stores' user-related effectivenesses (URES), with and without a thermostatic mixing-valve being employed}

The URE is an indicator of the store's effectiveness to deliver DHW to the user. This relative performance number should include the effects of stratification, heat losses from the store to the environment as well as the heat-transfer efficiency and recovery effects related to the store's HX, and thus take into account all the significant characteristics of the store, which affect its performance under daily-life operation. The URE is a performance indicator of a store relative to an ideal store, which would achieve $100 \%$ stratification, no heat losses to the environment and an infinite heat-transfer coefficient of the store's HX. The URE is defined as the ratio of the energy content to the volume of the withdrawn DHW divided by the ratio of the energy content to the volume of ideally withdrawn DHW out of an ideal store, i.e.,

$$
\mathrm{URE}=\frac{E_{\mathrm{DHW}} / V_{\mathrm{hx}, \mathrm{DHW}}}{E_{\mathrm{DHW}, \text { ideal }} / V_{\mathrm{hx}, \mathrm{DHW}, \text { ideal }}} .
$$

The general equation also can be written as:

$$
\mathrm{URE}=\frac{c_{\mathrm{w}} \int_{0}^{t=24 \mathrm{~h}} \dot{m}_{\mathrm{hx}}\left(T_{\mathrm{hx}, \text { out }}-T_{\mathrm{cw}}\right) \mathrm{d} t / \int_{0}^{t=24 \mathrm{~h}} \dot{m}_{\mathrm{hx}} \mathrm{d} t}{c_{\mathrm{w}} \int_{0}^{t=24 \mathrm{~h}} \dot{m}_{\mathrm{hx}, \text { ideal }}\left(T_{\mathrm{hx}, \text { out,ideal }}-T_{\mathrm{cw}}\right) \mathrm{d} t / \int_{0}^{t=24 \mathrm{~h}} \dot{m}_{\mathrm{hx}, \text { ideal }} \mathrm{d} t} .
$$

The UREs of the stores with a thermostatic mixing-valve are displayed in Fig. 15. The results obtained for the store without a thermostatic mixing valve, are very similar, (i.e., to within $1 \%$ ) and are therefore not discussed further here.

The numbers in Fig. 15 confirm that store $\mathrm{A}$ is the most effective of the analysed stores with respect to DHW supply. The difference between stores $\mathrm{A}$ and $\mathrm{C}$ reach $12 \%$. Here again, the design of the store and of the HX prove to be very influential.

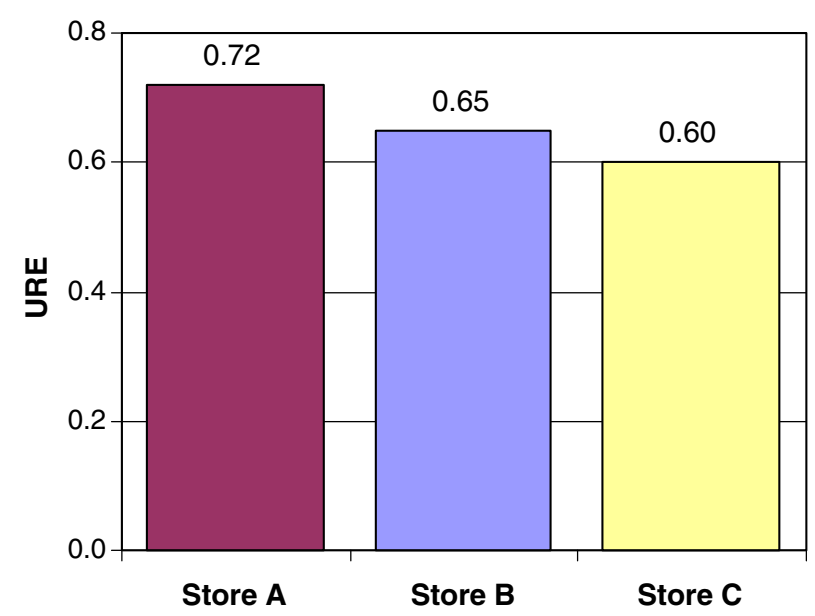

Fig. 15. URE values of stores $\mathrm{A}, \mathrm{B}$ and $\mathrm{C}$. 


\section{Conclusions}

- A TRNSYS simulation model of the behaviour of a novel stratified-store was developed and validated against measured data. The model takes into account the dynamic thermal behaviours of the store and the immersed HX and their effects on the predicted DHW temperatures.

- Experimental investigations with the stratified store were carried out to provide data for validation of the new simulation model for different DHW draw-off profiles. The validation showed good general agreement between experiment and simulation. The differences in the energy of the withdrawn DHW for the measurements and predictions were about $0.6 \%$.

- A methodology for comparing the behaviours of different DHW stores was developed, based on a daily course of discharging a store by a realistic withdrawal-profile for the DHW, with and without a thermostatic mixing-valve. Comparisons of DHW temperature levels, equivalent volumes and User Related Effectiveness UREs were suggested to determine the differences in the performances of the novel and two standard stores.

- The comparisons showed significant differences between each store's performance and the effectiveness of preparing the DHW. The inner arrangement of the immersed HX can significantly affect the stratification along the store height, the heat transfer and the recovery process of the immersed HX. The sophisticated inner configuration of the novel store improved its performance by up to $15 \%$. The store with the downwards coiled HX pipe showed adverse effects and a decreased performance by up to $20 \%$. The immersed HX position should be coiled upwards and located in the upper part of the tank in order to achieve a high rate of heat-extraction.

- The analysis revealed considerably higher performances and efficiencies of the novel stratified store compared with standard-design stores. The performance difference between that of new stratified store and standard ones reached over $20 \%$ when considering DHW delivery temperatures and 32\% when considering the hot-water equivalent volumes delivered.

- The URE index was developed to provide a store efficiency indicator as related to an ideal store. This performance number could find use for the classification of DHW stores. The URE of the novel stratified store was $72 \%$, whereas those for the two standard stores reached $65 \%$ and $60 \%$, respectively.

\section{References}

[1] prEN 13203. Qualification of domestic hot-water function of gas-fired appliances for domestic use. Brussels: European committee for standardization; 1998.

[2] Spur R, Fiala D, Nevrala D, Probert D. Influence of the domestic hot-water daily draw-off profile on the performance of a hot-water store. Appl Energ; to be published.

[3] Nevrala D. Detailed store description and configuration. Enplan 2000.

[4] Klein SA, Beckman WA, Mitchell JW, Duffie JA, Duffie NA, Freeman TL. TRNSYS 15 (a) transient simulation and program. Madison: Solar Energy Laboratory University of Wisconsin; 2000.

[5] Hensen JLM. On the thermal interaction of a building's structure with the heating-and-ventilation system. Doctoral dissertation, Eindhoven University of technology; 1991.

[6] Experimental laboratory measurements by Enplan. Private communication with D. Nevrala; 2003.

[7] Holman JP. Heat transfer. 6th ed. New York: McGraw-Hill; 1986. 